\title{
Study of the Hole-Formation Process with Different Mask Diameters via Through-Mask Electrochemical Machining
}

\author{
Hansong Li*, Chao Zhang, Guoqian Wang and Ningsong Qu \\ College of Mechanical and Electrical Engineering, Nanjing University of Aeronautics and \\ Astronautics, 210016, P.R. China \\ *E-mail address: hsli@nuaa.edu.cn
}

doi: $10.20964 / 2018.03 .46$

Received: 13 April 2017 / Accepted: 28 December 2017 / Published: 5 February 2018

\begin{abstract}
Hole array structure components are widely used in the aviation industry and other industries. The plates used in such parts are thin, the number of holes is large, the arrangement is close, and the hole sizes are inconsistent. All these characteristics make the hole array structure components difficult to be fabricated in one process. The through-mask electrochemical machining technology has advantages in the machining of hole array structure components with difficult-to-machine materials. Suitable diameters of mask holes can be selected according to the size of the to-be-processed holes to complete the machining of hole array structure components. However, the appropriate choice of the mask diameter is still a problem. In this paper, based on the finite element model of through-mask electrochemical machining, simulations were conducted on the hole-formation process with five different mask diameters: $0.2 \mathrm{~mm}, 0.3 \mathrm{~mm}, 0.4 \mathrm{~mm}, 0.5 \mathrm{~mm}$, and $0.6 \mathrm{~mm}$. The hole-formation rules with different mask diameters were then obtained. To prove the simulation rules, the corresponding experimental study was performed using a $0.2-\mathrm{mm}$ Ni-based superalloy plate. The simulation rules were verified, and a relationship figure between the diameters of fabricated holes and the machining time was obtained. Suitable masks can be selected according to this figure to fabricate holes with required diameters.
\end{abstract}

Keywords: through-mask electrochemical machining; finite element simulation; hole arrays with different diameters

\section{FULL TEXT}

(C) 2018 The Authors. Published by ESG (www.electrochemsci.org). This article is an open access article distributed under the terms and conditions of the Creative Commons Attribution license (http://creativecommons.org/licenses/by/4.0/). 